\title{
AN ELECTRON MICROSCOPIC STUDY OF THE DEVELOPMENT OF AXONS AND DENDRITES BY HIPPOCAMPAL NEURONS IN CULTURE
}

\section{Cells Which Develop Without Intercellular Contacts ${ }^{1}$}

\author{
WILLIAM P. BARTLETT ${ }^{2}$ AND GARY A. BANKER ${ }^{3}$ \\ Department of Anatomy, Albany Medical College, Albany, New York 12208 \\ Received May 17, 1983; Revised January 16, 1984; Accepted January 31, 1984
}

\begin{abstract}
We have studied the processes which are elaborated by hippocampal neurons in dissociated cell culture. Nerve cells, which were obtained from fetal rats at 18 to 20 days of gestation, were plated at very low density onto polylysine-treated coverslips and were maintained in serum-free medium. Under such conditions, some cells develop without contacting any neighboring neurons or glial cells. Examples of such isolated cells which had developed for 1 week in culture were studied first by light microscopy, then they were sectioned parallel to the substratum so that all portions of the cell and its processes could be examined by electron microscopy. Dendrites and axons could be clearly distinguished by both light and electron microscopy. Dendrites were rather thick at the base but tapered rapidly to a minimum diameter of about $0.5 \mu \mathrm{m}$ and contained polyribosomes throughout their length. Axons, which were several times longer than the dendrites, were thinner at the origin, tapered much less, and were essentially ribosome-free. These ultrastructural differences were particularly obvious at branch points, where cytoplasmic organelles tend to accumulate. Clusters of polyribosomes were invariably present at dendritic branch points, but they were never observed at axonal branch points. The axons most commonly arose from the proximal portion of a dendrite rather than directly from the cell body as they typically do in situ. These observations show that the fundamental differences in form and in the distribution of ribosomes between axons and dendrites can be established in cell culture. Contact with afferent fibers or with target cells during the period of process outgrowth is unnecessary for the expression of these features of axonal and dendritic differentiation.
\end{abstract}

An individual neuron can be viewed as a mosaic of structurally distinct cellular domains - cell body, dendrites, axon, and axon terminals - each serving a different role in neuronal function. Each can be recognized by its particular complement of cytoplasmic organelles, by the particular set of constituents in its plasma membrane, and by the interactions it enters into with other cells. Within each of these regions one can frequently distinguish subdomains, such as dendritic spines or axonal nodes of Ranvier. The earliest, and perhaps most fundamental, event in the establishment of neuronal domains is the development of the two distinct classes of neuronal processes, axons

${ }^{1}$ This work was supported by National Institutes of Health Grants NS 17112 and BRSG S07RR07394-20 and by an award from the Sinsheimer Fund. We wish to thank Ann Lohr for her expert technical assistance, Dr. Kevin Barron who kindly allowed us the use of his electron microscope facilities, Sue Easton for her advice concerning the electron microscopy, and Dr. Helen Molinari for her critical reading of the manuscript.

${ }^{2}$ Present address: Department of Anatomy, Wayne State University School of Medicine, Detroit, MI 48201.

${ }^{3}$ To whom correspondence should be addressed. and dendrites. One aim of our studies of hippocampal neurons in culture is to determine how this distinction between axons and dendrites arises and, ultimately, to determine the factors which control it.

In many respects, neurons which develop in dissociated cell cultures come to acquire the phenotypic properties of the corresponding neuronal cell type in vivo. This is reflected in the physiological properties of their membranes, in their ability to synthesize, release, and take up neurotransmitters, and in their ability to form synapses (for reviews, see Fischbach and Nelson, 1977; Nelson and Lieberman, 1981). Despite this, it is not yet certain to what extent neurons in such cultures can be said to develop structurally or functionally distinct axonal and dendritic domains. Bray (1973), among others, has noted that the processes which initially develop from neurons in culture are not obviously separable into these two categories. In particular, quite unlike the situation in vivo, one cannot recognize a single process originating from the cell body as the axon. For this reason, many investigators use the noncommittal term "neurites" to refer to the processes of nerve cells in culture.

We have chosen to study this issue using hippocampal cell cultures prepared at very low plating densities. By plating neuronal suspensions on coverslips and co-culturing these with 
monolayer cultures of astroglial cells growing on a separate substrate, it is possible to maintain the neurons for a sufficient period of time to enable their differentiation. Under such circumstances, some of the neurons are sufficiently far from neighboring cells that they can develop an extensive arbor of processes without contacting any other neurons or glial cells. At the desired time the coverslip, with neurons attached, can be removed for fixation and observation by light or electron microscopy.

Such isolated cells are of interest for two reasons. First, since the processes of one cell do not become intertwined with those of another, the complete form of an individual neuron is directly visible without the need for any special marking techniques. Moreover, because the cells grow directly on a planar substrate, a large proportion of a cell and its processes can be captured in a few electron microscopic sections cut parallel to the substrate. Thus, every portion of an individual cell can, in principle, be examined ultrastructurally. A second reason for studying such cells is to assess their capacity for development in the absence of contact with other cells. The growth of neurons in these low density cultures is obviously not completely independent of interactions with other cells. In fact, under these conditions the astroglial cells apparently release a trophic substance into the medium which the neurons require for their survival (Banker, 1980). Nevertheless, the many potential contact-mediated interactions which occur during the cells' normal development in situ cannot occur in such cultures.

We have previously described the light microscopic appearance of hippocampal neurons in low density cultures (Banker and Cowan, 1979). In the present paper we describe the appearance of these cells and their processes by electron microscopy in order to assess whether ultrastructurally distinct axons and dendrites can develop under such circumstances.

\section{Materials and Methods}

Preparation of cell cultures. Hippocampal neurons were prepared from the brains of 18-to 20-day-old rat fetuses as described in detail by Banker and Cowan (1977). At this stage of development, all hippocampal pyramidal cells have completed mitosis, but very few dentate granule cells have yet been generated (see Banker and Cowan, 1977). Cell suspensions were prepared by treating the hippocampi with trypsin $\left(0.25 \%\right.$ for $15 \mathrm{~min}$ at $\left.37^{\circ} \mathrm{C}\right)$, washing with $\mathrm{Ca}$ - and $\mathrm{Mg}$-free Hanks' balanced salt solution, and dissociating the tissue by repeated passage through a constricted Pasteur pipette. The nerve cells were plated at a density of 1500 to 2000 viable cells $/ \mathrm{cm}^{2}$ into $60-\mathrm{mm}$ culture dishes containing coverslips $16 \mathrm{~mm}$ in diameter which were prepared from Aclar 33C plastic film (Allied Chemical) and which had been treated with polylysine (Letourneau, 1975). After plating, the cells were incubated for 2 to $3 \mathrm{hr}$ in Eagle's Minimum Essential Medium (MEM) containing $10 \%$ horse serum to enable the neurons to attach to the substrate.

Since it has previously been shown that co-culture of hippocampal neurons with astroglial cells greatly enhances neuronal survival (Banker, 1980), this method was used for these experiments. Primary cultures containing predominantly astroglial cells, prepared from the cerebral hemispheres of neonatal rats according to the method of Booher and Sensenbrenner (1972) as modified by Kimelberg et al. (1978), were allowed to grow to confluence. Just before use the medium was removed, the glial cultures were rinsed with $\mathrm{MEM}$, and serum-free medium was added. This consisted of the supplements described by Bottenstein and Sato (1979) in their $\mathrm{N}_{2}$ mixture plus $0.1 \%$ ovalbumin, prepared in MEM. Then the hippocampal neurons, adherent to the Aclar coverslips, were transferred to the dishes containing astroglial cultures and were oriented with the nerve cells "down," facing the glial monolayer.

The long-term survival of the neurons apparently depends on a "conditioning" of the culture medium present in the small space inter vening between the neurons and glia. To enhance this effect, the medium was not changed in these experiments.

Preparation for electron microscopy. The cultures analyzed for this paper were fixed after 7 days in vitro. The coverslips containing the ncurons were turned cell side up, and the cells were fixed by adding $2 \%$ glutaraldehyde (at $37^{\circ} \mathrm{C}$ ) which had been prepared in culture medium. After $1 \mathrm{hr}$, the cultures were rinsed in phosphate buffer $(0.125 \mathrm{M})$ and postfixed for $30 \mathrm{~min}$ in $1.3 \%$ osmium tetroxide in this buffer. The cultures were then stained in $1 \%$ uranyl acetate in acetate buffer and were dehydrated through a graded series of ethanols. Coverslips were placed cell side up in individual containers and were covered with 3 to $4 \mathrm{~mm}$ of Epon 812 resin.

Following polymerization, the resin was removed from the container and the coverslip was peeled away, leaving the neurons at the surface of the resin block. The entire embedded culture was then stained with $1 \%$ toluidine blue in $1 \%$ borax at $60^{\circ} \mathrm{C}$ and temporarily attached to a glass slide for light microscopy. Appropriate cells were selected, circled with a diamond object marker, photographed, and punched out with a leather punch. The Epon "plug," containing the desired cell, was then cemented onto a plastic cylinder and trimmed for thin sectioning using the light micrographs as a guide. Prior to sectioning, the block face was sometimes rephotographed using an inverted microscope with a long working distance condenser.

Thin sections were prepared using a Porter-Blum MT-2 or LKB ultramicrotome with a diamond knife. The sections were picked up from the boat on a drop of water in the opening of an uncoated slot grid, as described by Galey and Nilsson (1966), then transferred to a second, Formvar-coated slot grid. The sections were stained with aqueous uranyl acetate and lead citrate and were examined using a Hitachi HU-11-E2 electron microscope.

Quantitative analysis. In the most favorable cases, a neuron and nearly all of its processes were included in a single thin section. More commonly full reconstruction of a cell required examination of several serial sections. A low magnification montage was first prepared showing the full length of each of the cell's processes. Using this as a guide, micrographs at higher magnification were taken at intervals of about $10 \mu \mathrm{m}$ measured from the center of the cell body. From these micrographs, segments $4 \mu \mathrm{m}$ in length were chosen for analysis; insofar as possible these segments were separated by $10 \mu \mathrm{m}$.

For each segment, the following measurements were made: process width (measured at right angles to the long axis of the process), segment area (length $\times$ average width), polyribosome density (expressed as number per square micrometer), and microtubule density (number per micrometer of process width). For purposes of analysis, polyribosomes were defined as small clusters or rosettes of at least five granules of relatively equal size and electron opacity. Process width and microtubule density were measured at both ends of each segment and were averaged.

In all, about 15 isolated cells were examined by transmission electron microscopy. Of these, six were chosen for detailed analysis.

\section{Results}

The arborization pattern of isolated hippocampal neurons. When hippocampal cultures are prepared at very low plating densities, a proportion of the neurons (on the order of $10 \%$ ) elaborate processes which do not contact other cells at any point. Figure 1 illustrates an isolated cell from such a culture after development for 7 days in vitro. Despite the absence of contact with other cells, this neuron has developed rather long processes which exhibit considerable branching. Such cells are not qualitatively different from cells of a comparable age in cultures established at much higher plating densities (see Bartlett and Banker, 1984). Isolated cells in low density cultures survive and continue to grow for 2 to 3 weeks, developing much more extensive and complex arborizations. However, such older cells proved unsuitable for electron microscopic analysis because their processes looped back, intersected one another, and became fasciculated, so that the branching pattern of individual processes could not be traced. Therefore, we restricted our analysis to nerve cells in 1-week-old cultures and examined cells whose processes remained separate from one another and did not form fiber bundles.

The cell shown in Figure 1 was selected for electron microscopic analysis for three reasons. First, it does not come into contact with any other cells. Two processes from a neighboring cell approach, but do not intersect, the processes of the cell to 


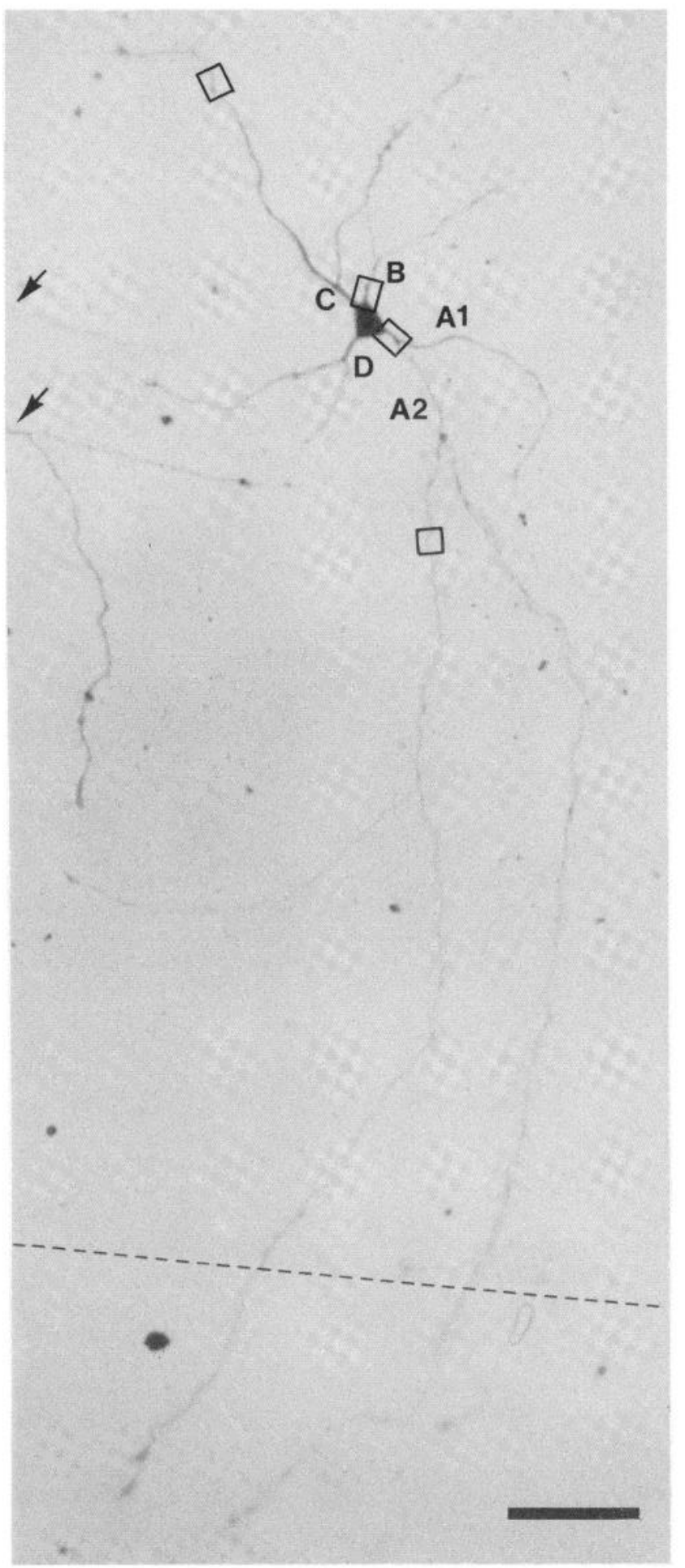

Figure 1. A photomicrograph of a 7-day-old hippocampal neuron grown in complete isolation from other neurons and glia. This neuron appears to have produced two different types of processes. Processes of the first type resemble dendrites in that they are relatively short, taper in diameter as they extend distally, and branch at "Y"-shaped angles (processes $B, C$, and $D$ ). In contrast, process $A_{2}$ resembles an axon in that it is thinner near its origin, shows little indication of tapering, and extends over $400 \mu \mathrm{m}$ from the cell soma. The neuronal processes entering the field from the left (arrows) arise from a neighboring neuron but do not contact the processes of the neuron under study at any point. The dashed line represents the edge of the trimmed block face. The enclosed rectangles indicate portions of the cell shown in Figure 3. Scale bar: $50 \mu \mathrm{m}$. be analyzed. Second, most of the processes which arise from this cell can be traced unambiguously to their termination. Only the distal branches of processes $\mathrm{B}$ and $\mathrm{C}$ and two branches of process $\mathrm{A}_{2}$ intersect one another and become fasciculated. Finally, the processes of this cell display many of the features which distinguish presumptive dendrites and axons in situ, as seen by light microscopy. The dendrite-like processes B, C, and $\mathrm{D}$ are relatively thick at their bases, decrease in diameter with increasing distance from the cell body, and are relatively short (terminating within a radius of about $150 \mu \mathrm{m}$ ). In this case, the overall dendritic pattern also bears a rudimentary resemblance to that of a hippocampal pyramidal cell, which is the predominant cell type in these cultures (Banker and Cowan, 1979). In contrast, process $\mathrm{A}_{2}$, although thinner near its origin, is several times longer than the presumptive dendrites and is much more uniform in diameter. This is quite characteristic of axons seen in situ. Based on the light micrograph, one cannot be certain if this presumptive axon arises directly from the cell body or from the proximal portion of a dendrite-like process; similarly, process $A_{1}$ might equally well be a dendritic branch or a short axon collateral.

The distribution of organelles within an individual neuron. A low magnification electron micrographic montage of this same cell is illustrated in Figure 2. The presence of many thin filopodia emanating from the soma and processes and attaching them to the substrate indicates that this section was taken very close to the surface of the coverslip on which the cell was growing. Nearly the full length of this cell's processes were contained within this single section (as indicated by the dashed line in Fig. 1). Because this section was so close to the substrate, all of the processes seen in the light micrograph, even the thinnest branches, were included in this section. Conversely, all of the processes seen in the electron micrograph, except for filopodia, could also be identified in the light micrograph.

The principal ultrastructural features of the soma and of the proximal processes of this cell can be seen in Figure 2. The cytoplasm contains a multitude of free polyribosomes but few profiles of rough endoplasmic reticulum. The nucleus, which has apparently been sectioned near its undersurface, is rather irregular in outline and shows clumps of chromatin beneath the nuclear membrane. These features are typical of immature neurons. Occasional microtubules can be seen along the periphery of the perikaryon and continuing into the cell's processes.

Some of the features of this cell's processes are illustrated at higher magnification in Figure 3. Figure $3 A$ shows the origin of one of the presumptive dendrites. Microtubules funnel into this process from the cell body and become aligned in parallel with the long axis of the process. Many free polyribosomes are scattered among the microtubules, as are mitochondria and coated vesicles. This process branches about $10 \mu \mathrm{m}$ from the soma. The cytoplasmic organelles found within the process, such as polyribosomes and mitochondria, show a pronounced accumulation in the fork of this branch point.

Electron micrographs illustrating more distal portions of a presumptive dendrite (at $110 \mu \mathrm{m}$ from the soma) and of a branch of the presumptive axon (at $90 \mu \mathrm{m}$ from the soma) are shown in Figure 3, $B$ and $C$. At this distance, the processes are 2 to 3 times thinner than at their origin. Microtubules are prominent features of both types of processes, and both contain occasional mitochondria and cisterns of smooth endoplasmic reticulum. Polyribosomes, however, although present in the dendritic process, are not seen in this portion of the axon. It is difficult to judge the consistency of this difference from individual examples such as these, but, since a large fraction of this cell could be studied electron microscopically, it was possible to determine the density of polyribosomes throughout much of this cell's arborization. This result is shown in Figure 4. On this basis, the difference between the two classes of processes 


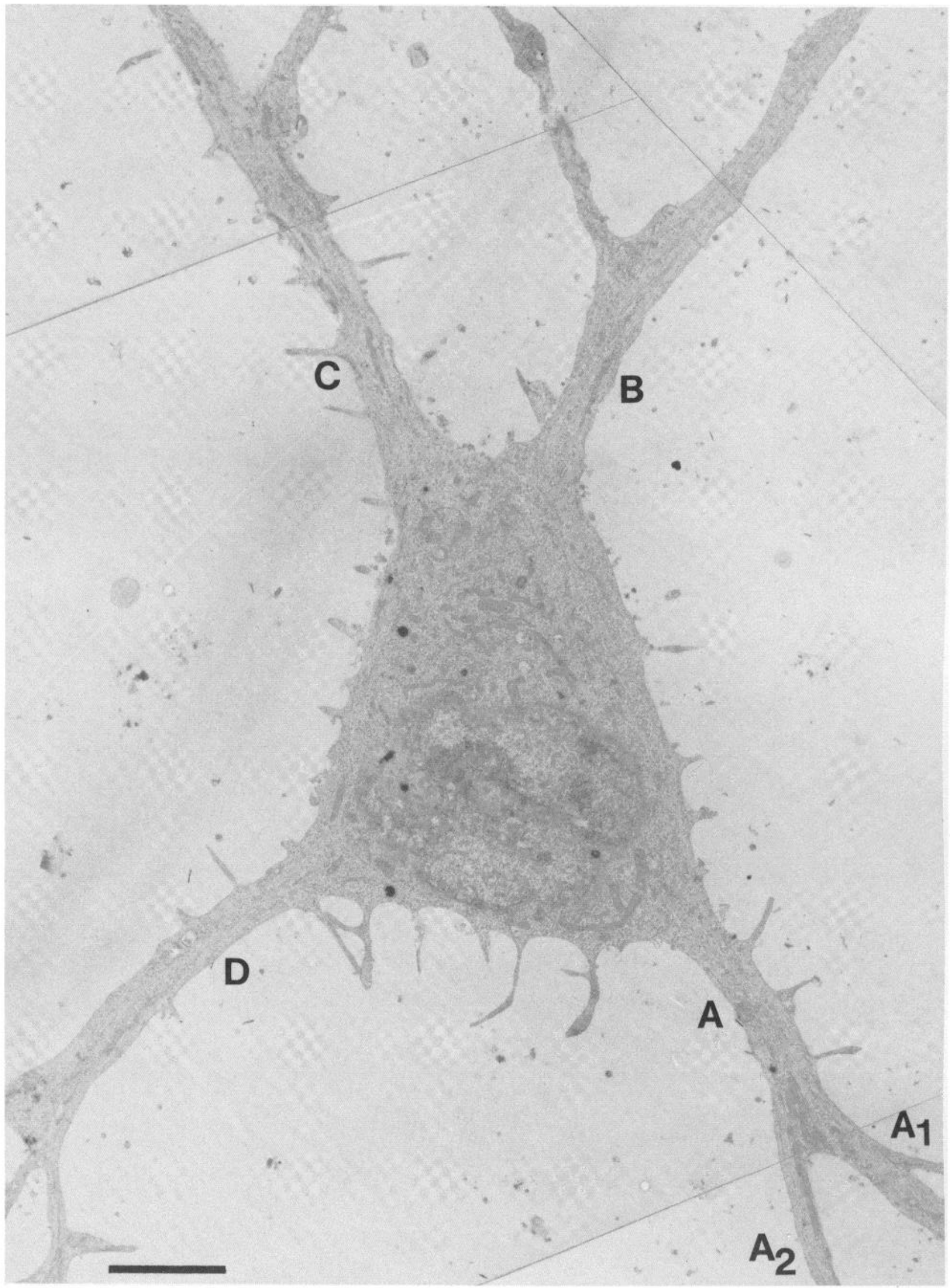

Figure 2. An electron micrographic montage of the neuron shown in Figure 1, illustrating its cell body and the origin of its four processes. The cell body contains many free polyribosomes and mitochondria, which also extend into the processes. Many filopodia arise from both the cell body and processes. Scale bar: $4 \mu \mathrm{m}$. 

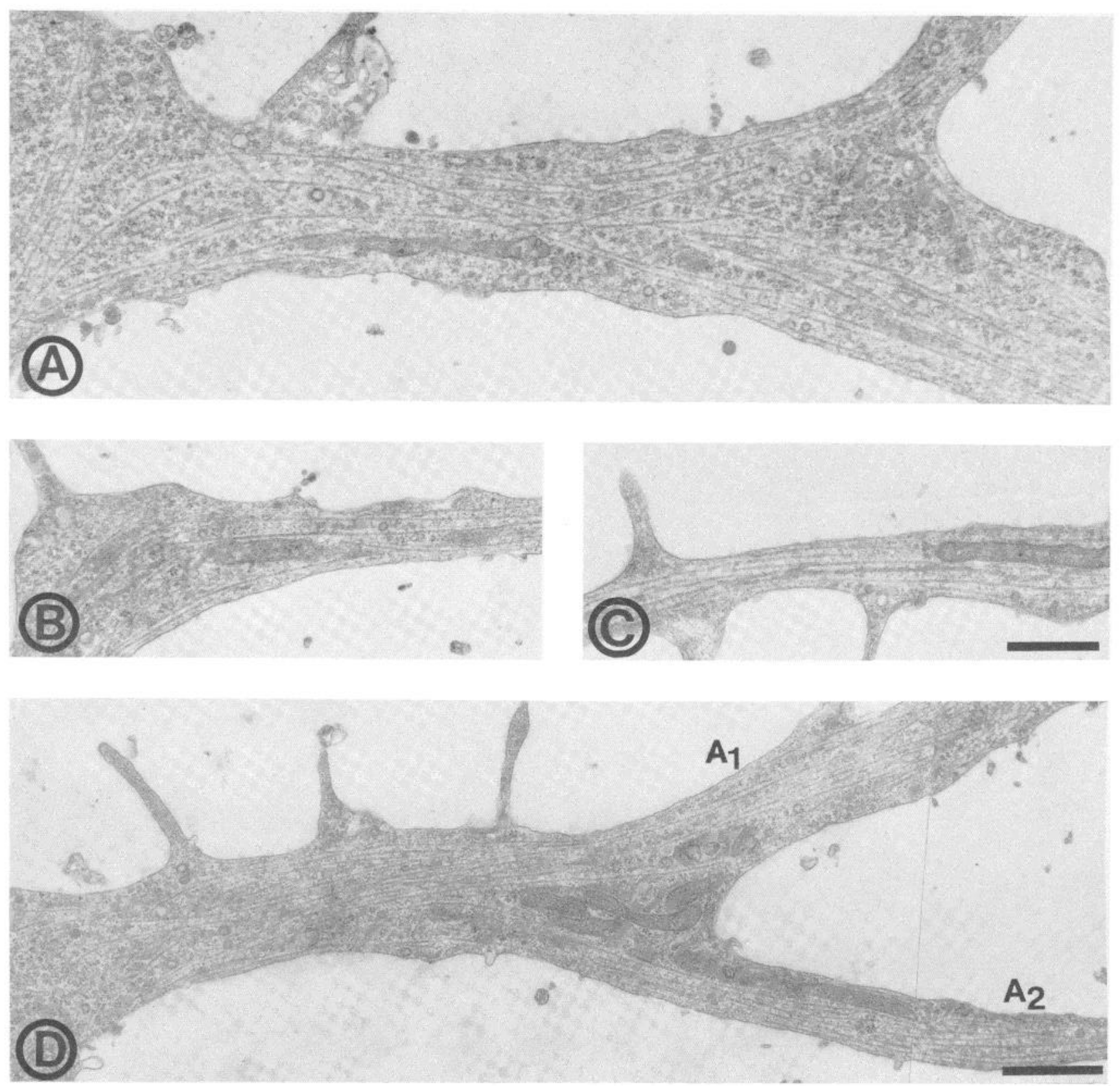

Figure 3. Electron micrographs illustrating portions of the processes of the neuron shown in Figure 1. $A$ illustrates the origin of one dendritelike process (process B). Ribosomes are found at the base of this process, in the angle of its branch point, and extending into each of its branches. $B$ shows one of the branches of this dendrite at $110 \mu \mathrm{m}$ from the soma, and $C$ shows one branch of the presumptive axon (process $A_{2}$ ) at $90 \mu \mathrm{m}$ from the soma. The features of the distal and proximal portions of the dendrites are similar, although the density of polyribosomes decreases distally (compare $A$ and $B$ ). In contrast, ribosomes are essentially absent in the presumptive axon. $D$ shows the origin of process $A$, from which the presumptive axon arises. The proximal portion of process A resembles the other three presumptive dendrites in that it contains numerous polyribosomes, which are especially concentrated at its first branch point. Beyond this point the features of one branch, $A_{2}-$ the presumptive axon-change. Most notably, the density of polyribosomes decreases markedly. This process, which continues for over $400 \mu \mathrm{m}$, is essentially ribosome-free throughout. The other branch, $A_{1}$, contains ribosomes throughout its length. Scale bar: $A, B$, and $C, 1 \mu \mathrm{m} ; D, 1.5 \mu \mathrm{m}$.

of this cell is striking. Polyribosomes are present in all of the processes judged to be dendrites by light microscopy. The density of polyribosomes within the presumptive dendrites is variable and declines with distance from the cell body, but in most instances they extend as far as the dendritic growth cone. In contrast, polyribosomes are only rarely found in the axon.

The origin of the axon of this cell is shown in Figure $D$. Surprisingly, the base of the process which gives rise to the axon is identical in its appearance with the cell's dendritic processes. It contains a profusion of polyribosomes as well as mitochondria and coated vesicles, which have accumulated at its most proximal branch point. Beyond this point one of the daughter branches, $A_{2}$, rapidly takes on the features of the axon. Immediately beyond this branch point, its width becomes reduced to about $0.5 \mu \mathrm{m}$ and remains at about this value over all of the rest of its length. Concurrently, ribosomes become extremely rare. This initial portion of the axon lacks the dense membrane undercoating or the fasciculation of microtubules which characterize the initial segment of mature axons in situ (Peters et al., 1976). No such change occurs in the features of 


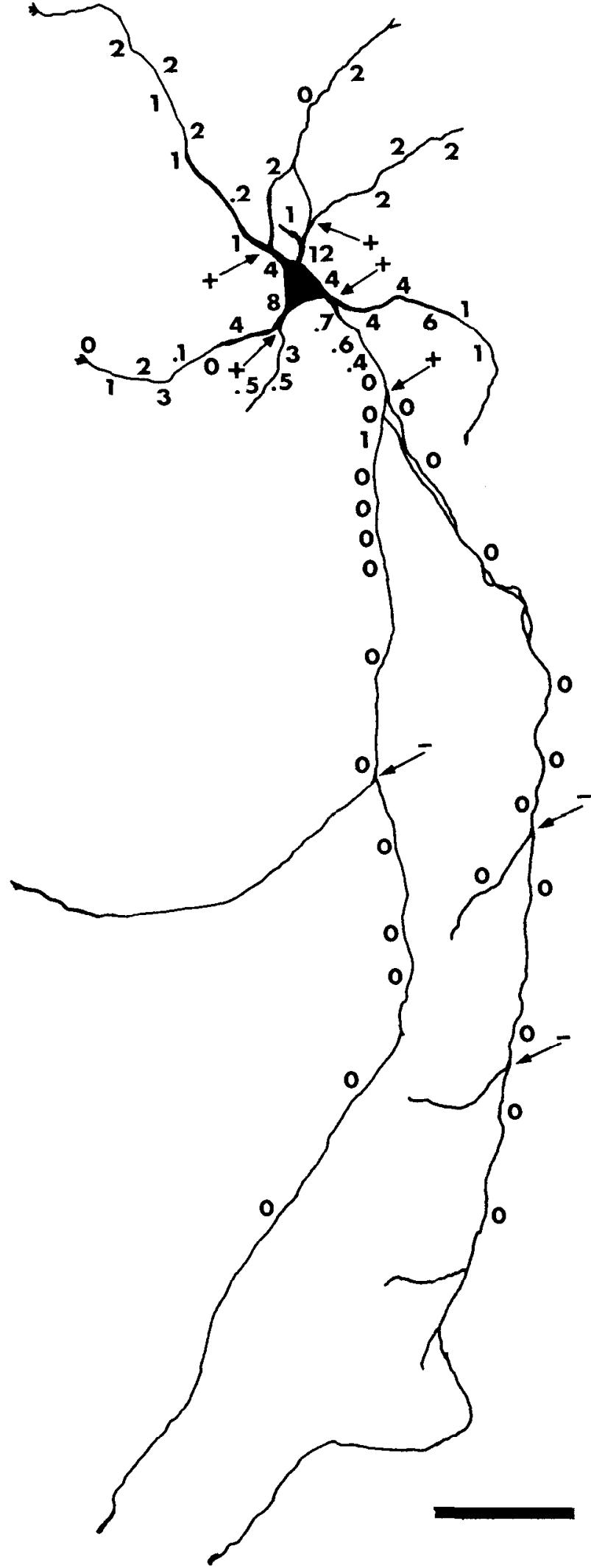

Figure 4. A drawing of the neuron seen in Figure 1 illustrating the distribution of ribosomes in its processes. The figures represent the density of polyribosomes (number per square micrometer) at each of the indicated positions along the cell's processes. Arrows point to branch points which contain (+) or lack (-) polyribosomes. Ribosomes are found throughout the full length of the dendrite-like processes but rapidly decrease in numbers in the axon-like process $\mathrm{A}_{2}$ soon after its origin from process $\mathrm{A}$. Ribosomes are found at each dendritic branch point but not at axonal branch points. Scale bar: $50 \mu \mathrm{m}$. the other branch $\left(A_{1}\right)$, which contains polyribosomes and resembles the cell's other dendritic processes throughout its length. Thus, in this instance, the cell's axon appears to arise from the proximal portion of a dendrite rather than directly from the cell body.

Additional examples of isolated cells. Figure 5 illustrates several segments along a dendrite $(A, B$, and $C)$ and an axon $(D$, $E$, and $F$ ) of two other isolated cells from cultures which had been maintained for 7 days. The most obvious ultrastructural difference between them is that the axons contain few if any ribosomes. By contrast, polyribosomes are present along the full length of the dendrite as far as the base of the dendritic growth cone (Fig. $5 \mathrm{C}$ ). This difference can be most easily appreciated in electron micrographs of the points at which the processes branch (Fig. 5, $A$ and $D$ ). The organelles present along the process tend to accumulate at branch points, as if their transport had been slowed or interrupted. Dendritic branch points (Fig. 5A) invariably contained a pronounced accumulation of ribosomes ( 16 of 16 examples); ribosomes were not found at any of the 17 axonal branch points examined.

The complete arborization pattern of these two additional isolated cells is illustrated in Figure 6, and the density of polyribosomes in their processes is indicated. Both cells have several short, tapering dendrites, which contain ribosomes throughout, and a single long axon from which ribosomes are largely excluded. As is typical of most cells we examined, the axons of both of these cells arose from the proximal portion of a ribosome-containing, presumptive dendrite rather than from the cell body. One of the cells examined in this study (not illustrated) gave rise to two separate axons. One axon arose directly from the soma, the other from a dendrite.

It might he argued that the differences between the distribution of ribosomes in the presumptive axonal and dendritic processes are of no particular significance, but simply reflect the facts that ribosomes become less frequent at progressively greater distances from the soma and that the axons extend for longer distances than the dendrites. The data summarized in Table I, which compares the density of polyribosomes in dendrites and in the proximal portions of axons at equivalent distances from the cell body, indicate that this is not the case. Even in the proximal segments of axons, the density of ribo somes is 5 to 10 times lower than in the dendrites.

A comparison of the axons and dendrites illustrated in Figures 3 and 5 suggests that multivesicular bodies and coated vesicles are more common in dendrites than in axons. These organelles also tend to accumulate at dendritic, but not at axonal, branch points. To our knowledge, a differential distribution of these organelles has not been noted for either mature or developing neurons in situ.

One of the features that distinguishes dendrites by light microscopy is their tendency to taper. Because the resolution of light microscopy is not sufficient to measure this accurately for hippocampal cells in culture, we determined the width of the axonal and dendritic processes in the electron micrographs used for analysis of ribosome density. Since the sections were cut parallel to, rather than perpendicular to, the long axis of roughly cylindrical processes, the values obtained represent the width at the level of sectioning, and on average will be somewhat less than the true diameter. Nevertheless, these measurements provide an estimate of the relative diameter of the two classes of processes. Figure 7 illustrates the change in process width at increasing distances from the cell body for one of the neurons we have analyzed (the cell shown in Fig. 6B). The dendrites are relatively thick at the base but taper rapidly until they reach a minimum width of about $0.5 \mu \mathrm{m}$. In marked contrast, the axon is thinner at its origin, tapers only gradually over its initial 150 to $200 \mu \mathrm{m}$, and does not significantly decrease in thickness beyond this. Similar results were obtained for the neuron illustrated in Figure 1 (data not shown). 

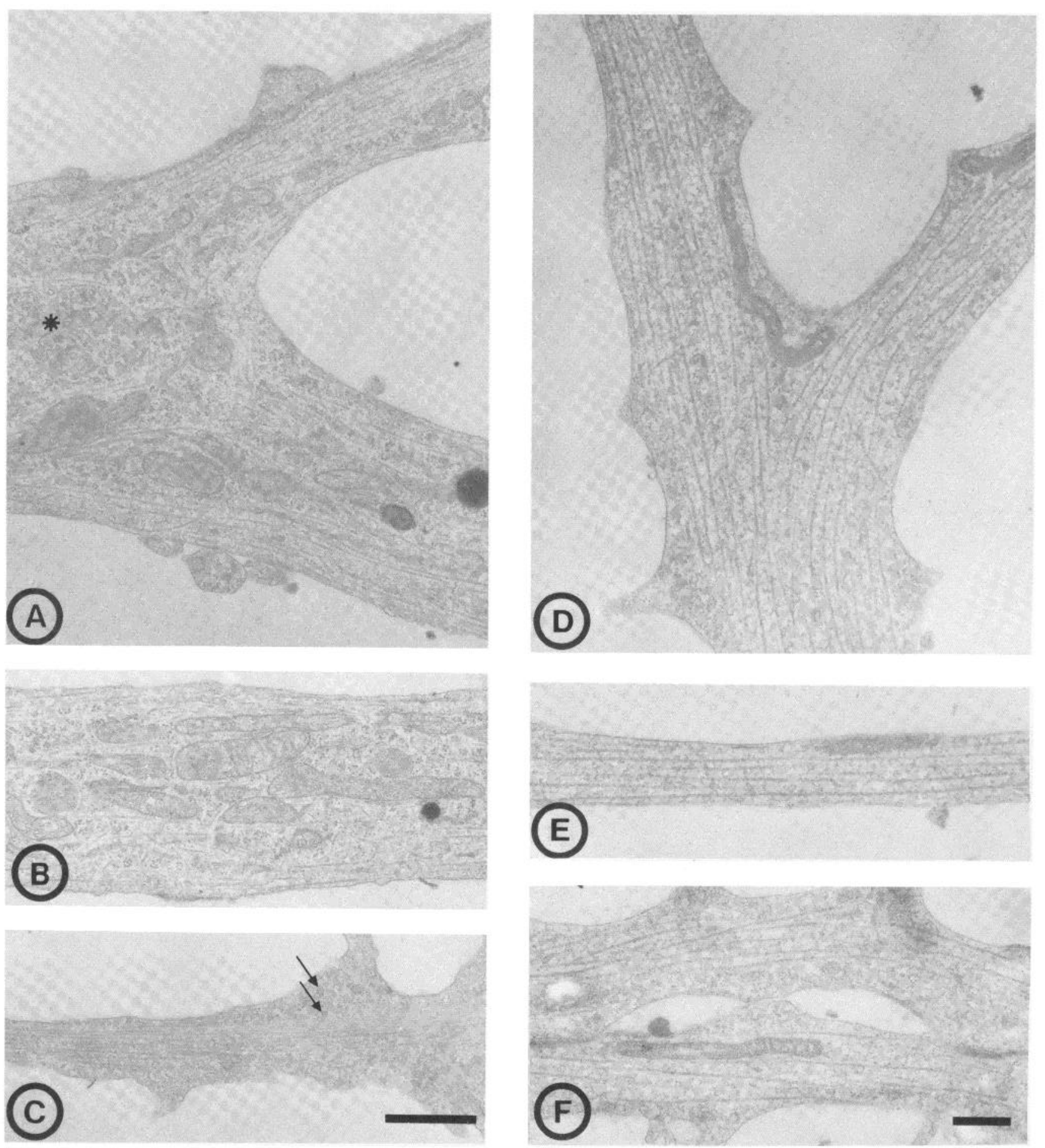

Figure 5. The ultrastructural features of the dendritic and axonal processes from two other isolated cells after 7 days in culture. $A, B$, and $C$ illustrate segments along a dendritic process at progressively greater distances from the soma (20 $\mu \mathrm{m}, 45 \mu \mathrm{m}$, and $90 \mu \mathrm{m}$, respectively). $D$ and $E$ illustrate segments of the axon of another cell at $380 \mu \mathrm{m}$ and $220 \mu \mathrm{m}$ from the soma. In $F$, at $520 \mu \mathrm{m}$ from the soma, the two most distal branches of this axon have become fasciculated. Note the presence of ribosomes in the dendrites and their pronounced accumulation at the branch point $(A)$. Even at the base of the dendritic growth cone $(C)$, where microfilaments become prominent, occasional ribosomes are present $(a r r o w s)$. Ribosomes are absent in the axon, even at branch points, where other organelles, such as mitochondria, accumulate. Multivesicular bodies (asterisk) are also common in dendrites. $A, B$, and $C$ are taken from the cell illustrated in Figure $6 A ; D, E$, and $F$ are from the cell illustrated in Figure $6 B$. Scale bar: $A, B$, and $C, 1 \mu \mathrm{m} ; D, E$, and $F, 0.5 \mu \mathrm{m}$.

Because there are differences in the density of microtubules in axons and dendrites in older hippocampal cultures (Bartlett and Banker, 1984), microtubule density (measured as number of microtubules per micrometer of process width) was determined for each of the three cells illustrated at each analysis point. No significant differences were found (axons: $8.6 \pm 2.8$ microtubules $/ \mu \mathrm{m}$; dendrites: $7.1 \pm 2.9$ microtubules $/ \mu \mathrm{m}$; mean $\pm \mathrm{SD})$.

\section{Discussion}

We set out to study the ultrastructural organization of individual hippocampal neurons in culture to determine if such 

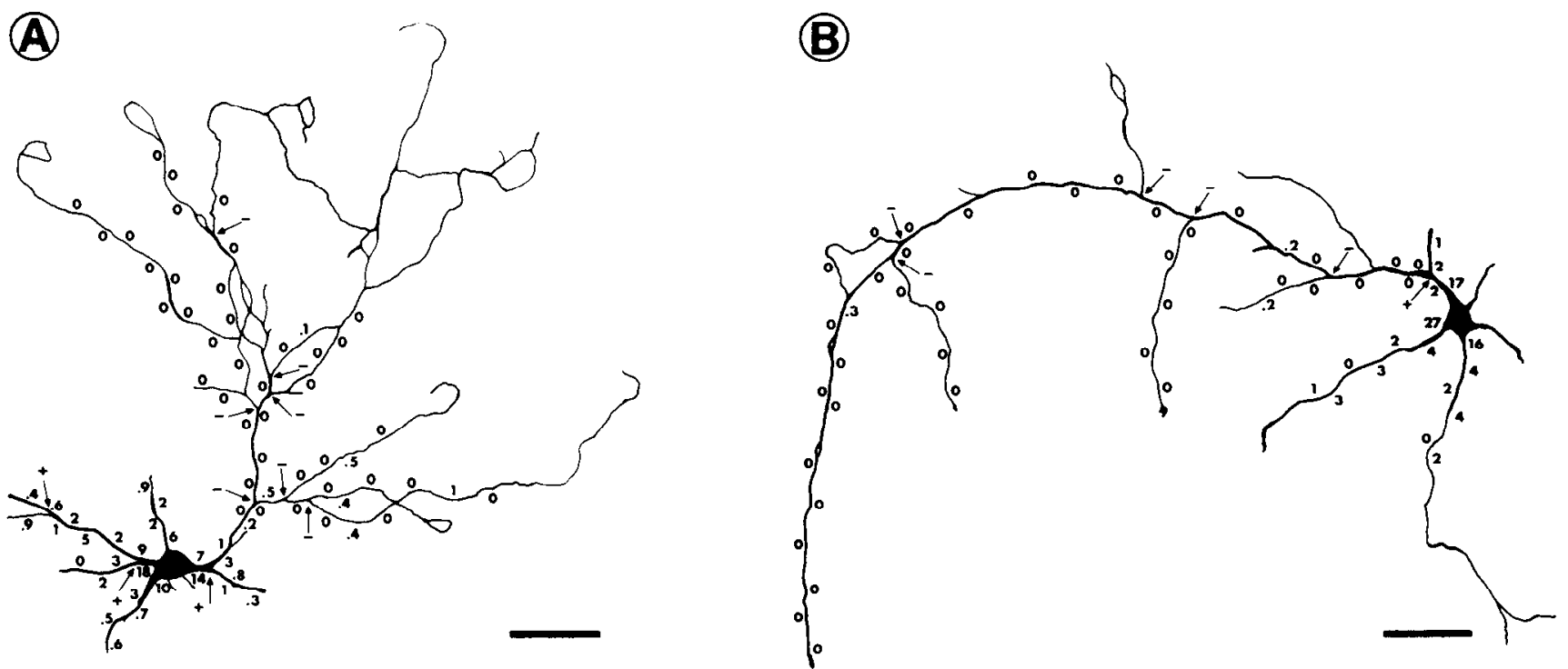

Figure 6. Drawings illustrating the distribution of polyribosomes in the processes of two isolated cells from cultures which had been maintained for 7 days. The values shown represent the density of polyribosomes per square micrometer. Arrows indicate branch points where polyribosomes were present (+) or absent (-). Scale bar: $50 \mu \mathrm{m}$.

TABLE I

Density of polyribosomes in axons and dendrites at comparable distances from the cell soma

\begin{tabular}{cccc}
\hline \multirow{2}{*}{ Region Analyzed } & \multirow{2}{*}{$\begin{array}{c}\text { Distance from } \\
\text { Cell Soma }\end{array}$} & \multicolumn{2}{c}{ Polyribosome Density $^{a}$} \\
\cline { 3 - 4 } & $\mu m$ & \multicolumn{1}{c}{ Axon } & \multicolumn{1}{c}{ Dendrites } \\
\hline Neuron 1 & $20-110$ & $0.25 \pm 0.4(N=11)$ & $2.1 \pm 1.7(N=37)$ \\
Neuron 2 & $20-100$ & $0.04 \pm 0.1(N=5)$ & $2.8 \pm 1.0(N=6)$ \\
Neuron 3 & $20-80$ & $0.43 \pm 0.1(N=12)$ & $1.8 \pm 1.6(N=16)$ \\
\hline
\end{tabular}

${ }^{a}$ Values shown are means $\pm \mathrm{SD} . N$ refers to the number of segments included in the analysis.

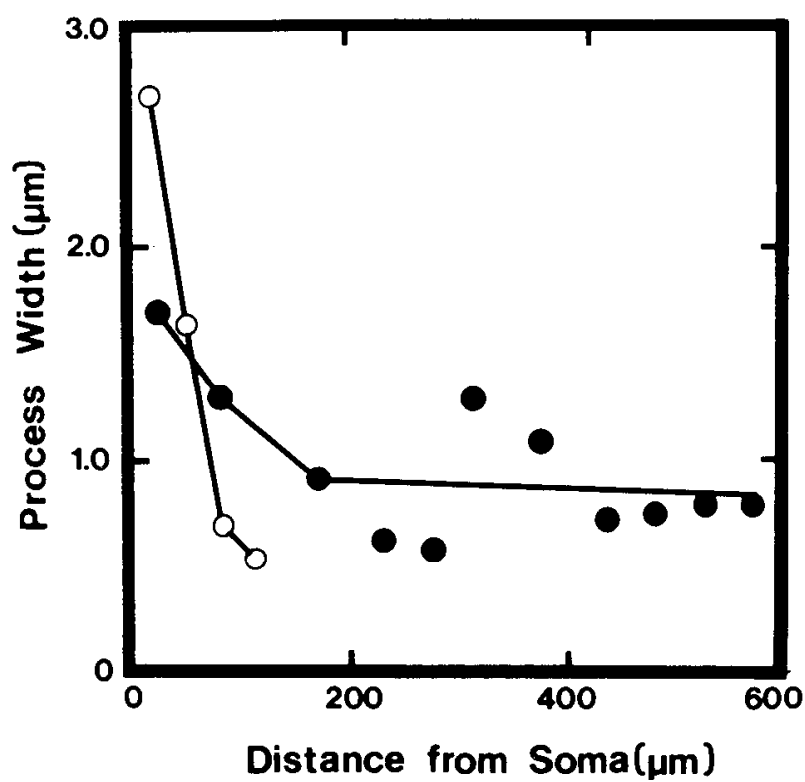

Figure 7. The change in width of the dendrites (open circles) and axon (solid circles) at increasing distances from the soma. These data are based on the cell shown in Figure 6B. There is a rapid decrease in the width of the dendrite-like processes at progressively greater distances from the cell soma. On the other hand, the axonal process and its branches taper only gradually over the first $200 \mu \mathrm{m}$ and do not decrease further at greater distances. cells could establish structurally distinct axonal and dendritic domains when grown in isolation. Our results demonstrate that, after 1 week's growth in culture, axonal and dendritic processes can be distinguished based on differences in their pattern of growth and in the organelles which they contain. These results show that contacts with other neurons or with glial cells during the period of nerve fiber outgrowth are not necessary for these aspects of axonal and dendritic differentiation to occur normally.

When neuronal processes that had been identified by light microscopy as presumptive axons and dendrites were compared by electron microscopy, the most obvious distinction between them was that ribosomes were consistently present in the presumptive dendrites but were only rarely encountered in presumptive axons. Because the density of polyribosomes declines in distal dendrites, and because polyribosomes are often clustered, they are not present in every segment of every dendrite. Nonetheless, when the density of polyribosomes is determined for all of the processes of a cell, the distinction between ribosome-containing and ribosome-poor processes is obvious. This exactly mirrors the situation in situ where, even at early stages of process development, ribosomes are common in dendrites but rare in axons (Tennyson, 1970; Peters and Feldman, 1973).

This distinction between the axonal and dendritic processes of cells in culture is especially obvious at points of fiber branching. Many of the organelles within the fibers, including mitochondria and various membranous elements, accumulate at the forks of branch points, as if their cytoplasmic transport were slowed or interrupted at these sites. In dendrites the local concentration of polyribosomes is several times greater at branch points than in intervening segments of the process. No ribosomes were observed at any of the axonal branch points examined.

Coated vesicles, coated pits, and multivesicular bodies were also observed more frequently in dendrites than in axons. These organelles are involved in receptor-mediated endocytosis and the uptake and intracellular transport of membrane receptors in neurons (Claude et al., 1982), as in other cell types (Goldstein et al., 1979; Pastan and Willingham, 1981). Coated vesicles and coated pits are also often seen near the postsynaptic membrane at developing synapses, suggesting that they might be involved in the localized insertion of specific membrane constituents 
such as transmitter receptors (Bursztajn and Fischbach, 1979, 1980) or of components of the postsynaptic density (Altman, 1971; Rees et al., 1976). At present we do not know the significance of their preferential localization in the dendrites of hippocampal neurons in vitro or if they display a similar differential distribution in the developing hippocampus in situ.

One inherent limitation of the present study is that only some of the morphological differences between axons and dendrites can be studied in the cultures we have examined. Many of the most obvious features which distinguish axons and dendrites in situ (reviewed by Peters et al., 1976), such as their synaptic polarity or the presence of dendritic spines or of a myelin sheath, cannot be applied to neurons which develop in isolation. Others appear only at later stages of neuronal maturation. For example, neurofilaments are uncommon in hippocampal neurons even after development for 3 weeks in culture, so that differences in the proportion of microtubules and neurofilaments cannot be used to distinguish axons and dendrites. We also failed to observe the morphological specializations characteristic of the axon initial segment. To our knowledge, these specializations have not been identified in dissociated cell cultures from the brain or spinal cord, even after longer periods of time in culture.

One aspect of the axonal organization of these cells is unusual: the axon most frequently arises from the proximal portion of a dendrite rather than directly from the cell body. This is occasionally seen in the hippocampus and in other regions in situ, but it is much more common for the axon to arise directly from the soma. This unexpected mode of axonal origin may be the rule rather than the exception for cells in culture. It has been observed following intracellular staining of cells in cultures prepared from spinal cord (Neale et al., 1978), cerebral cortex (Kriegstein and Dichter, 1983), and sympathetic ganglia (Wakshull et al., 1979). Some cells in hippocampal cultures also have more than one axon. These findings suggest that some facet of axonal development, which ordinarily ensures that a single axon emerges from the perikaryon of the cell, is disrupted in culture, although axonal elongation and differentiation are unimpaired. It would be of interest to know why this is so.

The developmental capacities of individual neurons. One issue of long-standing interest in developmental neurobiology concerns the possible importance of cell-to-cell contacts, and, in particular, of afferent innervation, on dendritic growth and dendritic form. Before considering the significance of the present results in this context, two questions must be considered. First, could cellular contacts have occurred in these cultures which were in some way overlooked? For example, could transient contacts have occurred at an earlier stage of growth in culture which elicited or influenced the differentiation of axons and dendrites, but which disappeared by the stage when the cells were studied? This cannot have been a frequent occurrence because the cells are often quite far from their nearest neighbor and because extensive degeneration of cells and their processes is not a consistent finding during the first week in vitro. Although a small fraction of the isolated cells seen at day 7 might have been contacted by another neural process at an earlier stage, the differentiation between axons and dendrites in isolated cells is much too consistent a finding to be explained on this basis.

Isolated cells can innervate themselves (Landis, 1977), and it might be argued that this plays a role in regulating axonal and dendritic development in vitro. In fact, no autapses were observed on any of the isolated cells examined in these experiments. Autapses might occur in older cultures where extensive contacts occur between processes of the same cells, but they are not necessary for the development described in this paper.

A second question concerns the possible influence of cell-cell interactions which occur in situ, before the cells are taken from the fetus, on their subsequent growth in vitro. At present this question cannot be satisfactorily answered. Based on Golgi and electron microscopic studies of neuronal development in the hippocampus and in neocortex (Shoukimas and Hinds, 1978; Nowakowski and Rakic, 1979), together with studies of thymidine incorporation (Banker and Cowan, 1977; Schlessinger et al., 1978), it seems probable that most hippocampal pyramidal cells would have established axons and some would have initiated dendritic development at the time they were taken for culture. Although these processes disappear after dissociation and plating into serum-containing medium, ${ }^{4}$ some cytoskeletal organization might persist within the perikaryon which could influence the new processes which subsequently develop in culture (see Solomon, 1981). However this may be, our results show quite clearly that no cellular contacts need be present. during the period of process extension and differentiation for structurally distinct axonal and dendritic domains to develop.

Our results raise several important additional questions. One concerns the sequence of events leading to the differentiation of axons and dendrites in vitro. After development for 1 or 2 days in culture, a typical cell has extended several short processes which cannot readily be distinguished as axons or dendrites by light microscopy. It may be that these processes are initially "indifferent," each later being influenced to develop as an axon or a dendrite. Alternatively, the development of each process may be determined from the outset, but the differences among them may not initially be recognizable. It could also be, as suggested by Rothman and Cowan (1981), that all of the initial processes are, in fact, dendrites, the development of axons being delayed in culture. The answers to these questions will provide a necessary foundation for studies of the cellular mechanisms which control the synthesis, transport, assembly, and restriction of particular neuronal constituents during axonal and dendritic development.

A second question concerns the distribution of constituents present in the plasma membranes of the axons and dendrites which develop in culture. In situ the restriction of particular membrane proteins, such as receptors for neurotransmitters or voltage-sensitive ion channels, to particular regions of the cell is of special functional significance. It will be important to determine the distribution of such constituents in neurons which develop in isolation and whether this can be modified when contacts with other cells are permitted.

Finally, it is important to establish if the axons and dendrites which develop in culture participate in interactions with other cells in the same highly selective way that they do in situ. For example, when myelination occurs in culture, are only axonal processes ensheathed, or does myelin form haphazardly on both dendrites and axons? When synaptogenesis occurs in culture, do axons and dendrites recognize one another appropriately so that they acquire their normal synaptic relationships, or are synapses formed indiscriminately? Observations bearing on this latter question are presented in the following paper (Bartlett and Banker, 1984).

Note added in proof. Denis-Donini et al. (1984) have recently shown that co-culture of mesencephalic dopaminergic neurons with striatal as opposed to mesencephalic glial cells greatly

\footnotetext{
${ }^{4}$ Since cells with processes are present immediately after dissociation, and since roughly the same proportion of cells have similar processes 2 to $3 \mathrm{hr}$ later, we had assumed that these residual processes were retained (Banker and Cowan, 1977). Recently, having photographed cells 30 to $60 \mathrm{~min}$ after plating, we found that the original processes are lost or retract and new processes form (or re-form) within $2 \mathrm{hr}$. The retraction of the residual processes appears to be induced or accelerated by introducing the cells into medium containing serum.
} 
influences the branching pattern of their neurites. They have suggested that contact between neuronal processes and specific subpopulations of glia may induce dendritic rather than axonal growth. We would emphasize that hippocampal neurons are capable of establishing both axonal and dendritic processes in the absence of contact with any glial cells or with their target neurons.

\section{References}

Altman, J. (1971) Coated vesicles and synaptogenesis. A developmental study in the cerebellar cortex of the rat. Brain Res. 30: 311-322.

Banker, G. A. (1980) Trophic interactions between astroglial cells and hippocampal neurons in culture. Science 209: 809-810.

Banker, G. A., and W. M. Cowan (1977) Rat hippocampal neurons in dispersed cell culture. Brain Res. 126: 397-425.

Banker, G. A., and W. M. Cowan (1979) Further observations on hippocampal neurons in dispersed cell culture. J. Comp. Neurol. 187: 469-494.

Bartlett, W. P., and G. A. Banker (1984) An electron microscopic study of the development of axons and dendrites by hippocampal neurons in culture. II. Synaptic relationships. J. Neurosci. 4: 1954-1965.

Booher, J., and M. Sensenbrenner (1972) Growth and cultivation of dissociated neurons and glial cells from embryonic chick, rat and human brain in flask cultures. Neurobiology 2: 97-105.

Bottenstein, J. E., and G. H. Sato (1979) Growth of a rat neuroblastoma cell line in serum-free supplemented medium. Proc. Natl. Acad. Sci. U. S. A. $76: 514-519$.

Bray, D. (1973) Branching patterns of individual sympathetic neurons in culture. J. Cell Biol. 56: 702-712.

Bursztajn, S., and G. D. Fischbach (1979) Coated vesicles in cultured myotubes contain acetylcholine receptors. Soc. Neurosci. Abstr. 5: 477.

Bursztajn, S., and G. D. Fischbach (1980) Accumulation of coated vesicles bearing B'TX binding sites in brain-treated myotubes. Soc. Neurosci. Abstr. 6: 358.

Claude, P. F., F. Hawrot, D. A. Dunis, and R. B. Campenot (1982) Binding, internalization, and retrograde transport of ${ }^{125} \mathrm{I}$-nerve growth factor in cultured rat sympathetic neurons. J. Neurosci. 2 : 131- 442 .

Denis-Donini, S., J. Glowinski, and A. Prochiantz (1984) Glial heterogeneity may define the three-dimensional shape of mouse mesencephalic dopaminergic neurones. Nature 307: 641-643.

Fischbach, G. D., and P. G. Nelson (1977) Cell culture in neurobiology. In Handbook of Physiology. Sect. 1: The Nervous System, Part 2, pp. 719-774, American Physiological Society, Bethesda, MD.

Galey, F. R., and S. E. G. Nilsson (1966) A new method for transferring sections from the liquid surface of the trough through staining solutions to the supporting film of a grid. J. Ultrastruct. Res. 14: $405-415$.
Goldstein, J. L., R. G. W. Anderson, and M. S. Brown (1979) Coated pits, coated vesicles, and receptor-mediated endocytosis. Nature 279: $679-685$.

Kimelberg, H. K., S. Narumi, and R. S. Bourke (1978) Enzymatic and morphologic properties of primary rat brain astrocyte cultures and enzymatic development in vivo. Brain Res. 153: 55-77.

Kriegstein, A. R., and M. A. Dichter (1983) Morphological classification of rat cortical neurons in cell culture. J. Neurosci. 3: 1634-1647.

Landis, S. C. (1977) Morphological properties of the dendrites and axons of dissociated rat sympathetic neurons. Soc. Neurosci. Abstr. 3: 525 .

Letourneau, P. C. (1975) Possible roles for cell-to-substratum adhesion in neuronal morphogenesis. Dev. Biol. 44: 77-91.

Neale, E. A., R. L. MacDonald, and P. G. Nelson (1978) Intracellular horseradish peroxidase injection for correlation of light and electron microscopic anatomy with synaptic physiology of cultured mouse spinal cord neurons. Brain Res. 152: 265-282.

Nelson, P. G., and M. Lieberman (1981) Excitable Cells in Tissue Culture, Plenum Press, New York.

Nowakowski, R. S., and P. Rakic (1979) The mode of migration of neurons to the hippocampus: A Golgi and electron microscopic analysis in foetal rhesus monkey. J. Neurocytol. 8: 679-718.

Pastan, I. H., and M. C. Willingham (1981) Receptor-mediated endocytosis of hormones in cultured cells. Annu. Rev. Physiol. 43: 239250.

Peters, A., and M. Feldman (1973) The cortical plate and molecular layer of the late rat fetus. Z. Anat. Entwicklungsgesch. 141: 3-37.

Peters, A., S. L. Palay, and H.deF. Webster (1976) The Fine Structure of the Nervous System: The Neurons and Supporting Cells, W. B. Saunders Co., Philadelphia.

Rees, R. P., M. B. Bunge, and R. P. Bunge (1976) Morphological changes in neuritic growth cone and target neuron during synaptic junction development in culture. J. Cell Biol. 68: 240-263.

Rothman, S., and W. M. Cowan (1981) A scanning electron microscopic study of the in vitro development of dissociated hippocampal cells. J. Comp. Neurol. 195: 141-155.

Schlessinger, A. R., W. M. Cowan, and L. W. Swanson (1978) The time of origin of neurons in Ammon's horn and the associated retrohippocampal fields. Anat. Embryol. 154: 153-173.

Shoukimas, C. M., and J. W. Hinds (1978) The development of the cerebral cortex in the embryonic mouse: An electron microscopic serial section analysis. J. Comp. Neurol. 179: 795-830.

Solomon, F. (1981) Specification of cell morphology by endogenous determinants. J. Cell Biol. 90: 547-553.

Tennyson, V. M. (1970) The fine structure of the axon and growth cone of the dorsal root neuroblast of the rabbit embryo. J. Cell Biol. 44: $62-87$

Wakshull, E., M. I. Johnson, and H. Burton (1979) Postnatal rat sympathetic neurons in culture. I. A comparison with embryonic neurons. J. Neurophysiol. 42: 1410-1425. 